\title{
Polychlorinated biphenyls in residential soils and their health risk and hazard in an industrial city in India
}

\author{
Bhupander Kumar, Virendra Kumar Verma, Satish Kumar Singh, Sanjay Kumar, \\ Chandra Shekhar Sharma, Avinash B. Akolkar \\ National Reference Trace Organics Laboratory, Central Pollution Control Board, Delhi, India
}

\begin{abstract}
Significance for public health
The concentrations of polychlorinated biphenyls (PCBs) in soils from an industrial city in India were measured for the assessment of human health risk. PCBs composition profiles were dominated with tri-chlorinated and tetra-chlorinated biphenyls. The possible sources of PCBs contamination can be attributed to local industrial emissions and long range transport depositions. The daily intakes of PCBs, and corresponding incremental lifetime cancer risk and hazard quotient for humans were estimated and found to be lower than acceptable levels. This baseline study may provide database on persistent organic pollutants in tropical countries and may also be useful in risks assessment of the industrial pollutants on human population.
\end{abstract}

\section{Abstract}

Background. Polychlorinated biphenyls (PCBs) have never been produced in India, but were used in industrial applications. PCBs have been detected in environmental samples since 1966, and their sources in soils come from depositions of industrial applications, incinerators and biomass combustions. PCBs adsorb to soil particles and persist for long time due to their properties. Their close proximity may also lead to human exposure through ingestion, inhalation, dermal contact, and may exert neurotoxic, mutagenic and carcinogenic health effects.

Design and Methods. Residential soil from Korba, India, was extracted using pressurized liquid extraction procedure, cleaned on modified silica and quantified for PCBs. Soil ingestion was considered as the main exposure pathways of life-long intake of PCBs. Human health risk in terms of life time average daily dose, incremental lifetime cancer risk (ILCR) and non-cancer hazard quotient (HQ) were estimated using established guidelines.

Results. The estimated average ILCR from non dioxin like PCBs for human adults and children was $3.1 \times 10^{-8}$ and $1.1 \times 10^{-7}$, respectively. ILCR from dioxin like PCBs for human adults and children was $3.1 \times 10^{-6}$ and $1.1 \times 10^{-5}$, respectively. The HQ for PCBs was $6.3 \times 10^{-4}$ and $2.2 \times 10^{-3}$, respectively for human adults and children. Study observed that ILCR from non dioxin like PCBs was lower than acceptable guideline range of $10^{-6}-10^{-4}$, and ILCR from dioxin like PCBs was within the limit. HQ was lower than safe limit of 1.

Conclusions. Study concluded that human population residing in Korba had low health risk due to PCBs in residential soils.

\section{Introduction}

During the past decades, toxic persistent organic compounds have been synthesized and released into the environment for direct or indirect application. Among them, chlorinated pesticides, polycyclic aro- matic hydrocarbons (PAHs), polychlorinated dibenzo-p-dioxins and dibenzo- $p$-furans (PCDDs/Fs) and polychlorinated biphenyls (PCBs) are more environmental and human health concern. ${ }^{1}$ PCBs are odourless, tasteless, colourless or light colour synthetic chemical compounds. These are highly stable compounds and were primarily used in electrical and industrial applications such as in transformers and capacitors, lubricants, flame retardants, plasticizers, paint additives, etc. ${ }^{2}$ There are no known natural sources of PCBs, they originate in the environment solely from anthropogenic sources including leakages from electrical transformers, waste disposals and spillage, and their contamination sources in soils are particularly from particulate and gaseous depositions from industrial applications. ${ }^{3}$ PCBs may also be released into the environment by the burning of some wastes in municipal and industrial incinerators. Building materials, such as caulking may also constitute a source of PCB contamination in the buildings and in surrounding soil. PCBs contents in building with caulking materials in USA found up to $81 \mathrm{mg} / \mathrm{kg}$ in dust and 3.3 to 34 $\mathrm{mg} / \mathrm{kg}$ in surrounding soils. ${ }^{4,5}$

Due to lipophilicity, toxicity, tendency to accumulate in food chains, and low chemical and biological degradation, PCBs have been banned globally under the Stockholm Convention on POPs. ${ }^{1}$ Non-ortho-substituted PCBs that exhibit dioxin-like activities similar to 2,3,7,8-tetrachorinated dibenzo-p-dioxin (TCDD), based on their ability to interact with and activate the Ah receptor (AhR), are known as dioxin-like PCBs (DLPCBs). The World Health Organization (WHO) and US Environmental Protection Agency (USEPA) has proposed toxic equivalency factors (TEFs) for dioxin-like PCBs based on comparison with TCDD, which is considered to be the most potent congener of PCDDs/Fs. PCBs, especially DL-PCBs exposure through ingestion, inhalation and skin contact have long been recognized for their potential to cause health effects in wide variety of plants and animal species including humans. Human exposure to these compounds has been associated with their adverse affect on endocrine system, in addition to being neurotoxic, mutagenic, and carcinogenic in the liver, biliary tract and skin. ${ }^{6,7}$ Occurrence of PCBs in remote areas, far from their original sources is thought to be the result of long range atmospheric transport and precipitation. ${ }^{8}$ PCB in the environment altered their compositions through various processes such as volatilization and partitioning, chemical or biological transformation, and bioaccumulation. PCBs adsorb strongly to soil, where they tend to persist due to their characteristic properties and, ${ }^{7}$ soil acts as a good indicator of pollution and environmental risks.

Accumulation of PCBs in soil may lead to contamination of vegetables and food chains. ${ }^{2}$ The close proximity of soils to humans may also lead to human exposure through the consumption of contaminated food, and occupational exposure via ingestion, inhalation and dermal contact pathways. High content of these pollutants in soils may cause health risks to the living beings exposed to it. Therefore, several studies have been conducted around the world for assessing the status of human and environmental health risk due to PCBs in soils. ${ }^{9-17}$ 
PCBs have never been produced in India but used in industrial applications. ${ }^{18}$ India is party to the Stockholm Convention with the objectives of intention of reducing and ultimately eliminating these pollutants.

Studies have been carried out in India, on the evaluation of PCBs in environmental matrices. ${ }^{19-23}$ However, available reports on assessment of human health risk due to PCBs are less in numbers, ${ }^{24+25}$ particularly, PCBs in soils and their risk were reported for North India, but no study was carried out in Central India. So, we determined 28 PCBs including 12 dioxin-like PCBs in residential soil and their health risk in the industrialized Korba city in Central India. This baseline data was compared with other studies, which may be useful in risks assessment of the industrial pollutants on human population.

\section{Design and Methods}

\section{Study area and sampling}

Korba, the study area, is located in the centre of the Korba District in Chhattisgarh, India (Figure 1) with the population of $\sim 5 \times 10^{5}$. It is situated between geographical coordinates of $22^{\circ} 01$ ' - $23^{\circ} 01^{\prime}$ latitude and $82^{\circ} 08^{\prime}-83^{\circ} 09$ longitude. Korba is enriched with coal and water resources (Hasdeo and Ahiran rivers) essential for power generation. Therefore, Korba is also known as Power City with several thermal and one hydro electric power plants generating more than $3650 \mathrm{MW}$ of electricity. Besides these, one major aluminum plant is also operational in this area. Region experiences a typical climate, where April to June is summer, from June to October it is raining season with an average rainfall of $1500 \mathrm{~mm}$, and winter season falls in November to February.

Sampling was carried out during June 2012 from twenty two locations.
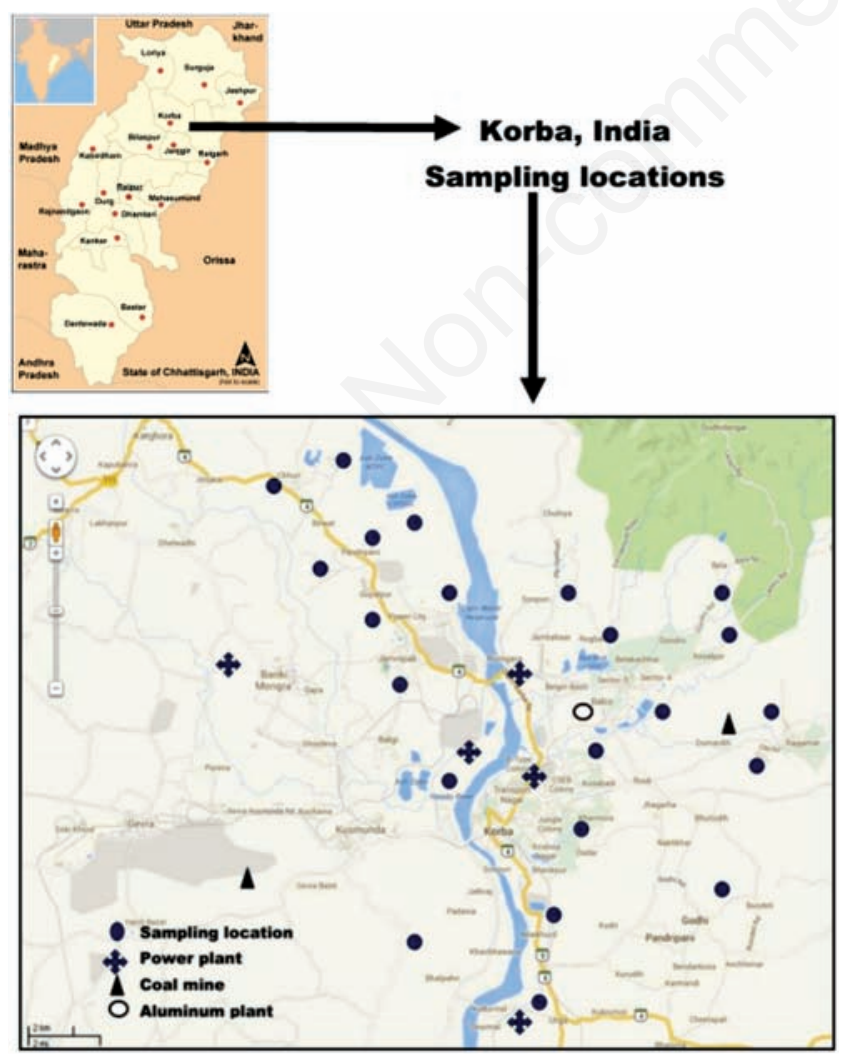

Figure 1. Map showing study area and sampling locations.
From each sampling location, approximately 500 grams of soil was collected in duplicates, and mixed thoroughly to ensure the representative sample from each location. An aliquot of homogenized soil was transferred to clean and labelled wide mouth amber glass containers. After labelling the sample containers, they were transported ice preserved to the laboratory and kept in refrigerator until further extraction.

\section{Chemicals and materials}

HPLC grade solvents used in sample processing were procured from Merck, India. Silica gel (100-200 mesh) procured from Sigma-Aldrich (USA) and activated at $130^{\circ} \mathrm{C}$ for $16 \mathrm{~h}$. Anhydrous sodium sulphate (Merck, India) was cleaned with solvents and stored in the sealed desiccator. Reference standards of 28 PCB congeners were purchased from Dr. Ehrenstorfer (GmbH, Augsberg, Germany). Standard solutions with suitable concentrations were used for instrument calibration and other quality control analysis.

\section{Sample extraction and clean-up}

Soil samples were extracted using pressurized liquid extraction procedure as per USEPA's SW-846 Method 3545. 15-20 g sample was homogenized and dried by mixing with diatomaceous earth (ASE prep DE, Dionex, USA). The extraction was carried out with accelerated solvent extractor (ASE-350, Dionex, USA) using acetone: hexane (v/v, 1:1) in two cycles with $5 \mathrm{~min}$. static time. The ASE was operated at $1500 \mathrm{psi}$ and the oven was heated to $100^{\circ} \mathrm{C}$. The extracts were concentrated to $2.0 \mathrm{~mL}$ using Rotatory Vacuum evaporator (Eyela, Japan).

The multilayered glass column chromatography with modified silica was performed for extract clean up. Multilayered silica column $(300 \times 30$ $\mathrm{mm}$ ) was packed from bottom to up with $2.5 \mathrm{~g}$ silica gel, $4.0 \mathrm{~g}$ silver nitrate silica gel, 2.5 silica gel, 4.0 basic silica gel, 2.5 g silica gel, 12.0 $\mathrm{g}$ acid silica and $5.0 \mathrm{~g}$ anhydrous sodium sulphate. The column was prerinsed with $100 \mathrm{~mL}$-hexane before sample was loaded. The elution of PCBs was subsequently carried out using $170 \mathrm{~mL}$ hexane and concentrated to $2.0 \mathrm{~mL}$. The eluted extract was concentrated under gentle stream of pure nitrogen using Rotatory Vacuum evaporator and Turbo Vap (Caliper, USA) to $1.0 \mathrm{~mL}$ and transferred to auto sampler vial for PCBs analysis by gas chromatograph.

\section{Quantification of polychlorinated biphenyls and quality control}

Analysis of twenty eight PCB congeners (PCB-18, -37, -44, -49, -52, -70, $-74,-77,-81,-105,-114,-118,-119,-123,-126,-128,-138,-151,-156,-157$, $-167,-168,-169,-170,-177,-187,-189$ and -207$)$ was carried out using gas chromatograph (Shimadzu SPD 2010) equipped with autosampler and electron capture detector (ECD, $\left.{ }^{63} \mathrm{Ni}\right)$. One $\mu \mathrm{L}$ of clean sample extract was separated on HP-5MS column $(60000 \times 0.25 \mathrm{~mm} \times 0.25 \mu \mathrm{m}$ film). Initial column temperature of $170^{\circ} \mathrm{C}(1 \mathrm{~min})$ was increased to $270^{\circ} \mathrm{C}$ at

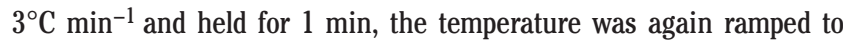
$290^{\circ} \mathrm{C}$ at $10^{\circ} \mathrm{C} \mathrm{min}^{-1}$ and finally holds for $3 \mathrm{~min}$. The injector and detector temperatures were kept at $225^{\circ} \mathrm{C}$ and $300^{\circ} \mathrm{C}$, respectively. Purified laboratory grade nitrogen gas was used as carrier.

During analysis, required quality assurance quality control (QA/QC) was performed with procedural blanks, random duplicate samples, multi-level calibration curves $\left(r^{2}, 0.999\right)$, calibration verification $(<5 \%)$ and matrix spiked recovery $( \pm 20 \%)$. Each sample extract was analysed in duplicate and the average of two analyses was used in calculations. The detection limit (DL) was calculated with signal to noise ratio $>3: 1$ by processing the eight aliquots of a spiked sample to produce a detectable response $(\mathrm{s} / \mathrm{n}>3)$ and multiplying the standard deviation by 3 ( $\mathrm{t}_{\text {students }}$ value for eight replicates at $99 \%$ confidence level). Statistically calculated value (DL) for all PCB congeners $(0.01 \mu \mathrm{g} \mathrm{kg}-1)$ was used during data interpretation. 


\section{Health risk assessment}

In this study, soil ingestion was considered as the main exposure pathways of life-long intake of contaminants in humans. Toxicity equivalency factors (TEFs) with reference to $2,3,7,8$,-TCDD have been assigned by World Health Organization for DL-PCBs for toxicity assessment. The toxic equivalent of DL-PCBs toxicity is expressed as toxic equivalent quotient (TEQ). Potential equivalent of carcinogenic dioxinlike PCBs was calculated using toxicity equivalency factors (TEFs). ${ }^{7}$

Toxic equivalent (ng $\left.\mathrm{WHO}_{2005}-\mathrm{TEQ} \mathrm{kg}-^{1}\right)=\mathrm{C} \times \mathrm{TEF}$

Where, $\mathrm{C}$ is the concentration of individual DL-PCB ( $\left.\mu \mathrm{gg}^{-1}\right)$ and TEF is the corresponding toxicity equivalency factor.

Incremental lifetime cancer risk (ILCR) and hazard quotient (HQ) was assessed by calculating the lifetime average daily dose (LADD) of PCBs. ${ }^{26,27}$ Equations used for estimating LADD, ILCR and HQ were as:

$$
\text { LADD }\left(\mathrm{mg} \mathrm{kg}^{-1} \mathrm{~d}^{-1}\right)=(\mathrm{Cs} \times \mathrm{IR} \times \mathrm{F} \times \mathrm{EF} \times \mathrm{ED}) /(\mathrm{BW} \times \mathrm{AT})
$$

Cancer Risk (ILCR) $=$ LADD $\times$ Cancer Oral Slope Factor $(\mathrm{CSF})$

$$
\text { Hazard Quotient (HQ)=LADD/RfD }
$$

Where, Cs is the pollutant concentration in soil $\left(\mu \mathrm{gg}^{-1}\right)$, IR is the soil ingestion rate $(\mathrm{mg} / \mathrm{kg} / \mathrm{d}), \mathrm{F}$ is the unit conversion factor, EF is exposure frequency (days/year), ED is the life time exposure duration (years), BW is the body weight $(\mathrm{kg})$, and AT is the averaging time for carcinogens (ED $\times \mathrm{EF}$ days). $\mathrm{CSF}$ is oral cancer slope factor (per $\mathrm{mg} / \mathrm{kg} /$ day). RfD is the reference dose of individual dioxin like PCBs (per $\mathrm{mg} / \mathrm{kg} /$ day). ${ }^{28}$ Input parameters for risk estimates are mentioned in Table $1.24,26,29,30$

Environmental health risk was carried out by comparing the PCBs levels in soils from Korba with stipulated guidelines for PCBs in soils for the protection of human and environment health. In India, guidelines for PCBs in soils have not yet established, therefore recommended guidelines from USA, New Zealand and Canada were adopted for the ecotoxicological risk assessment in this study. ${ }^{27,28,31}$

\section{Results}

\section{Distribution of polychlorinated biphenyls in soils}

In this study, we analysed twenty eight PCB congeners, including WHO's dioxin like PCBs in soils collected from different locations of Korba and their observed concentrations are presented in Table 2. The concentration of $\sum 28 \mathrm{PCBs}$ and $\sum 12 \mathrm{DL}-\mathrm{PCB}$ ranged between 3.25$25.22 \mu \mathrm{g} \mathrm{kg}^{-1}$ and $0.12-2.25 \mu \mathrm{g} \mathrm{kg}^{-1}$ with the mean and median value of $9.21 \mu \mathrm{gg}^{-1}$ and $0.65 \mu \mathrm{g} \mathrm{kg}{ }^{-1}$, and $8.22( \pm 1.17) \mu \mathrm{g} \mathrm{kg}^{-1}$ and 0.36 $( \pm 0.14) \mu \mathrm{g} \mathrm{kg}{ }^{-1}$, respectively (Table 2). PCB patterns were characterized in terms of individual homolog, but not by lower or higher chlorinated biphenyl. The PCB homolog pattern in soils at different locations is depicted in Figure 2. Tri- to tetra-chlorinated congeners were the major contributors and accounted for $88 \%$ to total PCBs and the contribution of remaining homolog is about $12 \%$. Average concentration of total 3CBs, 4CBs, 5CBs, 6CBs and 7CBs was $7.7 \mu \mathrm{g} \mathrm{kg}^{-1}, 2.8 \mu \mathrm{g} \mathrm{kg}^{-1}, 0.6$

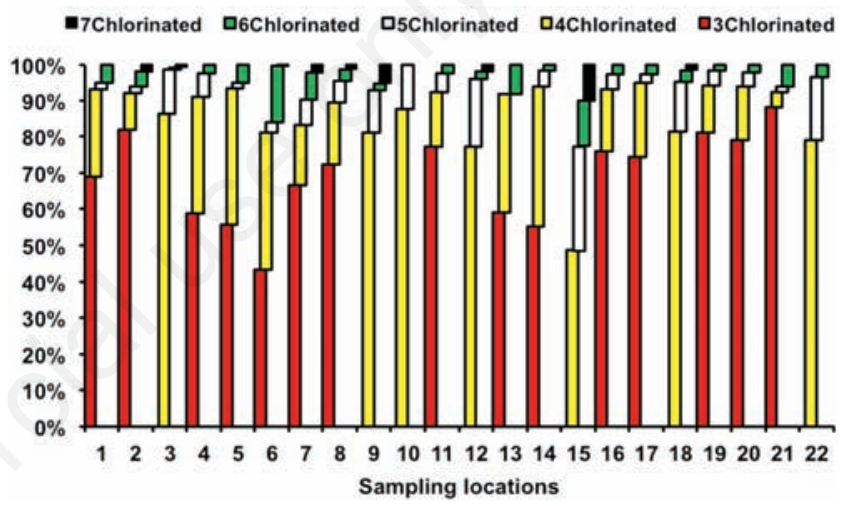

Figure 2. Polychlorinated biphenyls homolog pattern in soils at different locations.

\begin{tabular}{|c|c|c|c|c|}
\hline Symbol & Parameter & Unit & Point estimate & Ref. \\
\hline $\mathrm{Cs}$ & Concentration & $\mu \mathrm{kg}^{-1}$ & - & Present data \\
\hline IR & Soil ingestion rate & $\mathrm{mg} \mathrm{day}^{-1}$ & $\begin{array}{c}\text { adult } 100 \\
\text { children } 200\end{array}$ & 24 \\
\hline $\mathrm{EF}$ & Exposure frequency & days/year & 365 days/year & 24 \\
\hline $\begin{array}{l}\mathrm{LT} \\
(\mathrm{EF} \times \mathrm{ED})\end{array}$ & Life time & days & $\begin{array}{c}\text { adult } 25,550 \\
\text { children } 4382\end{array}$ & 24 \\
\hline $\mathrm{CSF}$ & Cancer slope factor & $\mathrm{mg} \mathrm{kg}^{-1} \mathrm{~d}^{-1}$ & $\begin{array}{c}\text { PCBs } 2 \\
\text { DL-PCBs }=1.5 \times 10^{5}\end{array}$ & 24 \\
\hline RfD & Reference dose & $m g \mathrm{~kg}^{-1} \mathrm{~d}^{-1}$ & 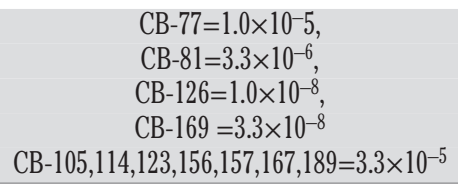 & 26 \\
\hline ED & Exposure duration & years & $\begin{array}{c}\text { adult } 70 \\
\text { children } 12\end{array}$ & 24,29 \\
\hline BW & Body weight & $\mathrm{kg}$ & $\begin{array}{c}\text { adult } 60 \\
\text { children } 35\end{array}$ & 30 \\
\hline
\end{tabular}

Table 1. Summary of input parameters used in calculation for health risk assessment. 
$\mu \mathrm{g} \mathrm{kg}-1,0.5 \mu \mathrm{g} \mathrm{kg}^{-1}$ and $0.2 \mu \mathrm{g} \mathrm{kg}^{-1}$, respectively. 3CBs (57\%) was the most dominant homolog followed by tetra-chlorinated (31\%).

The WHO toxicity equivalent quotient (TEQ) for 12 DL-PCBs varying greatly among locations, ranged between 1.52-64.32 ng-TEQ $\mathrm{kg}^{-1}$ with the mean and median values of $12.47 \mathrm{ng}-\mathrm{TEQ} \mathrm{kg}^{-1}$ and $7.41 \mathrm{ng}$ TEQ kg ${ }^{-1}\left( \pm 3.38 \mathrm{ng}^{-T E Q ~} \mathrm{~kg}^{-1}\right)$, respectively (Table 3$)$. Non ortho-PCB congener CB-169 was the main contributor and accounted for $>99 \%$ to total TEQ. Congener CB-169 represent the higher TEQ values which had the second high toxic potency after PCB-126 (toxic equivalency factor for 126 and 169 is 0.1 and 0.03 , respectively). PCB-126 concentration was below detection limit at all the locations, thus PCB169 was sole contributor and significantly increased the $\sum$ TEQ with the contribution of $>99 \%$.

\section{Human intake of polychlorinated biphenyls and health risk assessment}

Human adults and children may be exposed to PCB contaminated soils through different intake pathways. Due to carcinogenicity of PCBs

Table 2. Concentrations $\left(\mu \mathrm{g} \mathrm{kg}^{-1}\right)$ of polychlorinated biphenyls in residential soils from Korba, India.

\begin{tabular}{|c|c|c|c|c|c|}
\hline Congener & Range & Mean & Median & SE & इPCBs, \% \\
\hline PCB-18 & $1.65-20.41$ & 6.84 & 5.87 & 1.01 & 51 \\
\hline PCB-37 & $0.26-5.17$ & 1.62 & 1.06 & 0.35 & 6.4 \\
\hline PCB-44 & $0.33-2.52$ & 1.09 & 0.72 & 0.15 & 7.6 \\
\hline PCB-49 & $0.85-2.13$ & 1.34 & 1.14 & 0.11 & 5.3 \\
\hline PCB-52 & $0.17-2.16$ & 0.69 & 0.60 & 0.10 & 6.8 \\
\hline PCB-70 & $0.11-1.29$ & 0.47 & 0.44 & 0.06 & 3.9 \\
\hline PCB-74 & $0.08-1.35$ & 0.64 & 0.53 & 0.07 & 7.0 \\
\hline PCB-119 & $0.11-1.08$ & 0.49 & 0.39 & 0.06 & 4.3 \\
\hline PCB-128 & BDL & & & & \\
\hline PCB-138 & BDL & & & & \\
\hline PCB-151 & $0.05-0.29$ & 0.17 & 0.19 & 0.02 & 0.8 \\
\hline PCB-168 & BDL & & & & \\
\hline PCB-170 & BDL & & & & \\
\hline PCB-177 & $0.05-0.33$ & 0.15 & 0.12 & 0.02 & 0.6 \\
\hline PCB-187 & BDL & & & & \\
\hline PCB-207 & $0.06-0.34$ & 0.16 & 0.07 & 0.03 & 0.2 \\
\hline$\Sigma \mathrm{PCBs}$ & 2.99-23.47 & 8.62 & 7.95 & 1.09 & 93.5 \\
\hline PCB-77 & BDL & & & & \\
\hline PCB-81 & $0.06-0.23$ & 0.13 & 0.12 & 0.02 & 0.3 \\
\hline PCB-105 & BDL & & & & \\
\hline PCB-114 & $0.06-0.40$ & 0.17 & 0.14 & 0.02 & 0.8 \\
\hline PCB-118 & $0.06-0.14$ & 0.08 & 0.07 & 0.01 & 0.2 \\
\hline PCB-123 & $0.05-0.58$ & 0.23 & 0.19 & 0.04 & 0.8 \\
\hline PCB-126 & BDL & & & & \\
\hline PCB-156 & $\mathrm{BDL}$ & & & & \\
\hline PCB-157 & BDL & & & & \\
\hline PCB-167 & BDL & & & & \\
\hline PCB-169 & $0.05-2.14$ & 0.42 & 0.25 & 0.11 & 3.9 \\
\hline PCB-189 & $0.09-0.25$ & 0.16 & 0.14 & 0.01 & 0.5 \\
\hline$\Sigma$ DL-PCBs & $0.12-2.25$ & 0.65 & 0.36 & 0.14 & 6.5 \\
\hline$\Sigma 28 \mathrm{PCBs}$ & $3.25-25.22$ & 9.21 & 8.22 & 1.17 & 100 \\
\hline
\end{tabular}

SE, standard error; PCB, polychlorinated biphenyl; BDL, below detection limit. and intake of contaminated soil through ingestion, human adults and children may get exposure to PCBs. Therefore, PCBs and DL-PCBs exposure assessment was carried out by estimating the incremental life time daily dose (LADD) followed by potential cancer risk (incremental life time cancer risk) (ILCR) and non-cancer risk (hazard quotient, HQ). For this study, the calculated LADD, ILCR for human adults and children from non-DL-PCBs, DL-PCBs-TEQ and HQ were presented in Table 3. The LADD of non-DL-PCBs for adults and children was between $4.6 \times 10^{-9}-3.6 \times 10^{-8} \mathrm{mg} \mathrm{kg}^{-1} \mathrm{~d}^{-1}$ and $2.4 \times 10^{-8}-1.9 \times 10^{-7} \mathrm{mg}$ $\mathrm{kg}^{-1} \mathrm{~d}^{-1}$, with an average value of $1.3 \times 10^{-8} \mathrm{mg} \mathrm{kg}^{-1} \mathrm{~d}^{-1}$ and $6.8 \times 10^{-8}$ $\mathrm{mg} \mathrm{kg} \mathrm{kd}^{-1} \mathrm{~d}^{-1}$, respectively. However, the LADD of DL-PCB-TEQ for adults and children ranged between $2.2 \times 10^{-12}-9.2 \times 10^{-11} \mathrm{mg} \mathrm{TEQ} \mathrm{kg}^{-1} \mathrm{~d}^{-1}$ and $1.1 \times 10^{-11}-4.8 \times 10^{-10} \mathrm{mg}$ TEQ $\mathrm{kg}^{-1} \mathrm{~d}^{-1}$, respectively with the mean value of $1.8 \times 10^{-11} \mathrm{mg}$ TEQ $\mathrm{kg}^{-1} \mathrm{~d}^{-1}$ and $9.2 \times 10^{-11} \mathrm{mg}$ TEQ $\mathrm{kg}^{-1} \mathrm{~d}^{-1}$, respectively for adults and children.

Risks for human adults and children from non-DL-PCBs and DLPCBs were estimated in terms of incremental life time cancer risk (ILCR) and hazardous quotient (HQ). The estimated ILCR from nonDL-PCBs to adults and children was between $9.3 \times 10^{-9}-7.2 \times 10^{-8}$ and $4.8 \times 10^{-8}-3.7 \times 10^{-7}$, respectively, with an average value of $2.6 \times 10^{-8}$ and $1.4 \times 10^{-7}$, respectively. However, the ILCR from DL-PCB-TEQ to adults and children was in the range of $3.3 \times 10^{-7}-1.4 \times 10^{-5}$ and $1.7 \times 10^{-6}$. $7.1 \times 10^{-5}$, respectively with an average value of $2.7 \times 10^{-6}$ and $1.4 \times 10^{-5}$, respectively.

The non-carcinogenic hazard quotients (HQs) for human adults and children from PCBs exposure through soil ingestion pathway were quantified. The average HQs was $5.4 \times 10^{-4}$ and $2.8 \times 10^{-3}$ for adults and children respectively (Table 3 ), and ranged between $6.6 \times 10^{-5}$ to $2.8 \times 10^{-3}$ and $3.4 \times 10^{-4}$ to $1.4 \times 10^{-2}$ for adults and children respectively (Figure 3).

Table 3. Estimated polychlorinated biphenyls (PCBs) toxic equivalent quotient, and life time average daily dose, incremental life time cancer risk and hazardous quotient for adults and children due to PCBs exposure.

\begin{tabular}{|c|c|c|c|c|}
\hline Parameters & Rar & & Mean & Median \\
\hline & Min. & Max. & & \\
\hline $\begin{array}{l}\text { Toxic equivalent } \\
\left(\text { ng } \mathrm{WHO}_{2005} \text {-TEQ kg-1) }\right.\end{array}$ & 1.52 & 64.32 & 12.47 & 7.41 \\
\hline $\begin{array}{l}\mathrm{LADD}_{\text {Non DLPCBs }}\left(\mathrm{mg} \mathrm{kg}^{-1} \mathrm{~d}^{-1}\right) \\
\text { Adults } \\
\text { Children }\end{array}$ & $\begin{array}{l}5.4 \times 10^{-9} \\
1.9 \times 10^{-8}\end{array}$ & $\begin{array}{l}4.2 \times 10^{-8} \\
1.4 \times 10^{-7}\end{array}$ & $\begin{array}{l}1.5 \times 10^{-8} \\
5.3 \times 10^{-8}\end{array}$ & $\begin{array}{l}1.4 \times 10^{-8} \\
4.7 \times 10^{-8}\end{array}$ \\
\hline $\begin{array}{l}\text { LADD }_{\text {DL-PCBs-TEQ }}\left(\mathrm{mg} \mathrm{kg}^{-1} \mathrm{~d}^{-1}\right) \\
\text { Adults } \\
\text { Children }\end{array}$ & $\begin{array}{l}2.5 \times 10^{-12} \\
8.7 \times 10^{-12}\end{array}$ & $\begin{array}{l}1.1 \times 10^{-10} \\
3.7 \times 10^{-10}\end{array}$ & $\begin{array}{l}2.1 \times 10^{-1} 1 \\
7.1 \times 10^{-1} 1\end{array}$ & $\begin{array}{l}1.2 \times 10^{-11} \\
4.2 \times 10^{-11}\end{array}$ \\
\hline $\begin{array}{l}\text { ILCR }{ }_{\text {Non DL-PCBs }} \\
\text { Adults } \\
\text { Children }\end{array}$ & $\begin{array}{l}1.1 \times 10^{-8} \\
3.7 \times 10^{-8}\end{array}$ & $\begin{array}{l}8.4 \times 10^{-8} \\
2.9 \times 10^{-7}\end{array}$ & $\begin{array}{l}3.1 \times 10^{-8} \\
1.1 \times 10^{-7}\end{array}$ & $\begin{array}{l}2.7 \times 10^{-8} \\
9.4 \times 10^{-8}\end{array}$ \\
\hline $\begin{array}{l}\text { ILCR }_{\text {DL-PCBs-TEQ }} \\
\text { Adults } \\
\text { Children }\end{array}$ & $\begin{array}{l}3.8 \times 10^{-7} \\
1.3 \times 10^{-6}\end{array}$ & $\begin{array}{l}1.6 \times 10^{-5} \\
5.5 \times 10^{-5}\end{array}$ & $\begin{array}{l}3.1 \times 10^{-6} \\
1.1 \times 10^{-5}\end{array}$ & $\begin{array}{l}1.9 \times 10^{-6} \\
6.4 \times 10^{-6}\end{array}$ \\
\hline $\begin{array}{l}\text { HQ } \\
\text { Adults } \\
\text { Children }\end{array}$ & $\begin{array}{l}7.7 \times 10^{-5} \\
2.6 \times 10^{-4}\end{array}$ & $\begin{array}{l}3.2 \times 10^{-3} \\
1.1 \times 10^{-2}\end{array}$ & $\begin{array}{l}6.3 \times 10^{-4} \\
2.2 \times 10^{-3}\end{array}$ & $\begin{array}{l}3.7 \times 10^{-4} \\
1.3 \times 10^{-3}\end{array}$ \\
\hline
\end{tabular}

LADD, life time average daily dose; ILCR, incremental life time cancer risk; HQ, hazardous quotient; TEC, toxic equivalent quotient. 


\section{Discussion}

\section{Polychlorinated biphenyls in soils}

PCB-18 was the major congener and accounted for $51 \%$ of $\sum$ PCBs, the contribution of any other congener being less than 8\%. WHO's DLPCBs accounted for $6.5 \%$ to $\sum 28 \mathrm{PCBs}$. Non-Ortho PCBs were contributing comparatively more than mono-ortho PCBs to total DL-PCBs. PCB congener 169 was the dominant contributor and accounted for $60 \%$ to $\sum$ DL-PCBs.

In recently conducted studies, similar observations have been reported for PCBs in environmental matrices in India. ${ }^{19,21,23}$ Major activities such as combustion process, automobile exhaust and the industrial activities have been reported as potential sources of PCBs in industrial areas..$^{32}$

After release, PCB congeners in the ambient environment partition into the gaseous and particle phases. The partitioning of lower chlorinated congeners $(\mathrm{Cl} \leq 6)$ in the gas phase is higher compared with higher chlorinated congeners $(\mathrm{Cl} \geq 7) .33$ Thus, low chlorinated congeners undergo greater long-range atmospheric transport to areas outside their source site than the higher chlorinated congeners. The observed homolog pattern in this study may have originated from the short range atmospheric transport from industrial sites, ${ }^{17}$ and medium-range regional atmospheric deposition. ${ }^{9}$ Soils from the areas those having more activities such as open fires, cooking and heating in residential areas, may have higher concentrations of PCBs, especially during the winter season. During such activities, especially burning of mixtures of waste, containing garden wastes, paper, plastics, PVC (polyvinyl chloride) and painted wood may produce relatively large amount of dioxin like-PCBs.

\section{Global comparison of polychlorinated biphenyls in soils}

Concentrations of PCBs observed in soils from Korba were compared with the recent measurements in other soils around the world including India. The comparative information is presented in Table 4. ${ }^{10-17,22,23,33-38}$ The concentration ranges of PCBs observed in Korba (3.25-25.22 $\mu \mathrm{g}$ $\mathrm{kg}^{-1}$ ) were comparable to sampling locations in Kurukshetra, India, ${ }^{23}$ Beijing, China, ${ }^{10}$ Central Ghana, ${ }^{12}$ Estarreja, Portugal. ${ }^{14}$ However, PCB levels were lower when compare to Mazandaran and Guilan, Iran, ${ }^{15}$ Punjab, Pakistan, ${ }^{16}$ Delhi, India, ${ }^{22}$ Zhejiang, China, ${ }^{17}$ Guangdong, China, ${ }^{33}$ Moscow, ${ }^{35}$ North India, ${ }^{34}$ North America ${ }^{35}$ and USA. ${ }^{36-38}$ On the

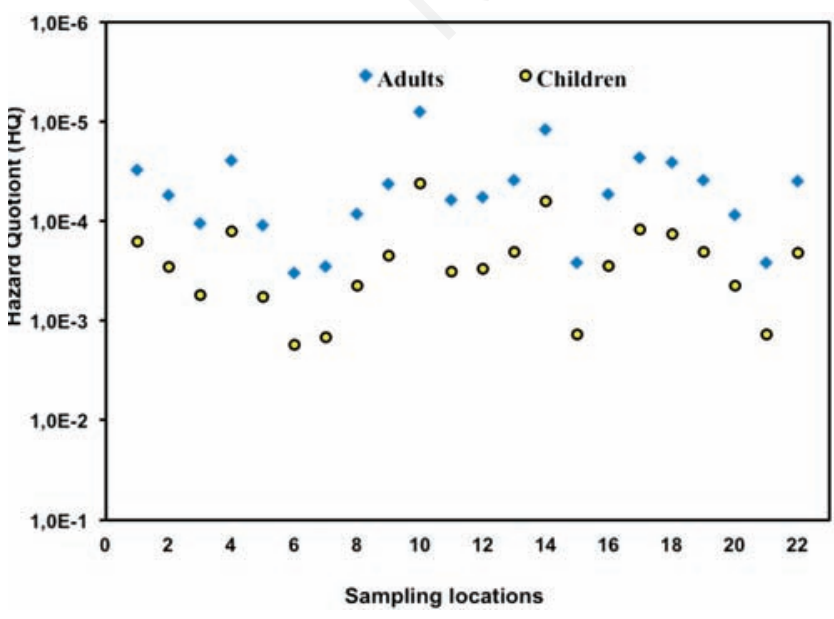

Figure 3. Hazard quotiont to adults and children due to total polychlorinated biphenyls exposure. other hand PCBs concentrations in our study were higher than those reported from Addis Ababa, Ethiopia, ${ }^{11}$ southeast China, ${ }^{13}$ Binzhou, China, ${ }^{34}$ Bursa, Turkey (Table 4). ${ }^{37}$

\section{Health risk estimates}

The estimated LADD of DL-PCBs-TEQ for adults and children corresponds to $0.018 \mathrm{pg}$ TEQ $\mathrm{kg}^{-1} \mathrm{~d}^{-1}$ or $0.126 \mathrm{pg}$ TEQ kg ${ }^{-1}$ week $^{-1}$ and 0.092 pg TEQ $\mathrm{kg}^{-1} \mathrm{~d}^{-1}$ or $0.644 \mathrm{pg}$ TEQ $\mathrm{kg}^{-1}$ week $^{-1}$, respectively. These estimated TEQ intakes for adults and children residing in Korba were lower when compared to recommended tolerable daily intake (TDI) or tolerable weekly intake (TWI) of TEQ set by the international agencies for safety of the public health. FAO/WHO and Agency for Toxic Substances and Disease Registry (ATSDR) and New Zealand Ministry of Health recommended the TDI for acute sub-chronic and chronic exposures to dioxins-TEQ as $1.0 \mathrm{pg}$ TEQ $\mathrm{kg}^{-1} \mathrm{~d}^{-1}{ }^{2,39,40}$ Environment Agency of United Kingdom recommended estimated adult intakes for PCDDs, PCDFs and dioxin-like PCBs as 2 pg WHO-TEQ $\mathrm{kg}^{-1} \mathrm{~d}^{-1}{ }^{41}$ European Commission's Scientific Committee for Food (SCF) recommended and fixed a TDI and TWI of $2 \mathrm{pg}$ WHO-TEQ $\mathrm{kg}^{-1} 14 \mathrm{pg}$ WHO-TEQ $\mathrm{kg}^{-1}$ for dioxins and DL-PCBs. ${ }^{40}$ In Asia, Japan established the comparatively higher TDI of dioxins as 4 pg-TEQ $\mathrm{kg}^{-1} \mathrm{~d}^{-1} .42$

The observed cancer risks and HQ from this study were compared with other available studies. The cancer risks in Korba were found to be comparable with Delhi (adults $6.04 \times 10^{-8}$, children $3.13 \times 10^{-7}$ ), ${ }^{22}$ Kurukshetra (adults $3.31 \times 10^{-8}$, children $1.71 \times 10^{-7}$ ) in India and Lisbon and Viseu in Portugal (adult $\left.1.4 \times 10^{-8}\right) .14,23$ But, cancer risk was lower than Midway Atoll, USA (adult $0.11 \times 10^{-6}$ ), Catalan, Spain (adult $3.1 \times 10^{-5}$ ), ${ }^{43}$ Zhejiang, China (adult $\left.6.50 \times 10^{-6}-1.24 \times 10^{-4}\right)^{44}$ and Finland (adult $2.3 \times 10^{-6}$ )..$^{45}$ The non-cancer risk in Korba were lower when compare with Delhi (adults 0.105, children 0.330),22 Kurukshetra (adults $1.69 \times 10^{-4}-1.09 \times 10^{-3}$, children $9.09 \times 10^{-3}-1.26 \times 10^{-2}$ ) in India, ${ }^{23}$ and Finland (adult, 0.8), ${ }^{46}$ but higher than those from Catalan, Spain (adults, $8.3 \times 10^{-5}$, children, $\left.8.9 \times 10^{-5}\right) .^{43}$

The estimated ILCR and HQs for residents of Korba were within acceptable risk limit of ILCR $\left(10^{-4}\right)$, and of HQs $(\mathrm{HQ}=1)$ indicating a low risk.

\section{Eco-toxicological health risk of polychlorinated biphenyls}

Environmental guidelines for PCBs in soil have not been established in India. Therefore, non-carcinogenic effects of PCBs on environmental health in this area were assessed by applying guideline levels from USA, Canada and New Zealand. The concentration levels of PCBs observed from this study for Korba were much lower than USA (500 $\mu \mathrm{g} \mathrm{kg}^{-1}$ and $5000 \mu \mathrm{g} \mathrm{kg}{ }^{-1}$, respectively for agriculture and, urban park and residential land use), ${ }^{27}$ Canada (500 $\mu \mathrm{g} \mathrm{kg}^{-1}$ to $33,000 \mu \mathrm{gg}^{-1}$ for different land use) ${ }^{28}$ and New Zealand (soil screening criteria for PCBs, $220 \mu \mathrm{g} \mathrm{kg}^{-1}$ and 20,000 $\mu \mathrm{g} \mathrm{kg}^{-1}$, respectively for residential and parkland areas). ${ }^{31}$ Therefore, study concluded with no environmental health risk and adverse effects on the soil micro-organisms, due to PCBs in studied soils.

\section{Conclusions}

The study concluded that concentrations of PCBs including dioxin like-PCBs were lower than recommended guidelines for soils for the protection of human and environmental health. Observed levels of PCBs were dominated with tri-chlorinated (3-Chlorine) and tetra-chlorinated (4-Chlorine) biphenyls. The possible sources of PCBs contamination in Korba can be attributed to local industrial emissions and long range 
Table 4. $\Sigma$ polychlorinated biphenyls in soils from India and other countries: comparison with present study.

\begin{tabular}{|c|c|c|c|c|}
\hline \multirow[t]{2}{*}{ Location } & \multirow[t]{2}{*}{ Land use } & \multicolumn{2}{|c|}{$\begin{array}{c}\text { ¿PCBs concentration } \\
\left(\mu \mathrm{g} \mathrm{kg}^{-1}\right)\end{array}$} & \multirow[t]{2}{*}{ Ref. } \\
\hline & & Range & Mean & \\
\hline Korba, India & Mixed & $3.25-25.22$ & 9.21 & This study \\
\hline Beijing, China & Urban & BDL-37.11 & 11.70 & 10 \\
\hline Addis Ababa, Ethiopia & Urban & $0.4-19$ & 3.80 & 11 \\
\hline Central, Ghana & Industrialized & $1.32-12.94$ & 8.17 & 12 \\
\hline Southeast, China & Industrialized & BDL-55.4 & 3.16 & 13 \\
\hline Estarreja, Portugal & Urban & $2.3-17$ & 8.8 & 14 \\
\hline Mazandaran and Guilan, Iran & Agriculture & $7.5-34.6$ & 25.7 & 15 \\
\hline Punjab, Pakistan & Mixed & $7-45$ & - & 16 \\
\hline Zhejiang, China & Industrialized & $0.61-127.33$ & - & 17 \\
\hline Delhi, India & Urban & $1.08-100.67$ & 21.16 & 22 \\
\hline Kurukshetra, India & Urban & $3.33-34.81$ & 11.57 & 23 \\
\hline Guangdong, China & Industrialized & $7.4-4000$ & $17-470$ & 33 \\
\hline Binzhou, China & Urban-rural & BDL-87 & 2.6 & 34 \\
\hline Moscow, Russia & Urban & $2.1-50.8$ & - & 35 \\
\hline North India & Agriculture & $<0.01-99.40$ & 18.83 & 36 \\
\hline Bursa, Turkey & Industrialized & $0.21-5.46$ & 2.12 & 37 \\
\hline North America & Grassland & $7.9-93$ & - & 35 \\
\hline Sauget, IL, USA & Industrialized & - & 487.2 & 36 \\
\hline Cedar Rapids, IA, USA & Garden & $3-1200$ & 56 & 37 \\
\hline Midway Atoll, USA & Military base & $2.6-148.8$ & 50.7 & 38 \\
\hline
\end{tabular}

transport depositions. Estimated daily intakes of PCBs including dioxin like PCBs, and corresponding health risks, in terms of ILCR and HQ were lower than safe acceptable levels for human adults and children.

Correspondence: Bhupander Kumar, National Reference Trace Organics Laboratory, Central Pollution Control Board, East Arjun Nagar, Delhi 110032, India.

Tel.: +91.011.431.02378.

E-mail: bhupander_kumar@yahoo.com

Key words: residential soil, polychlorinated biphenyls, dioxin like toxicity equivalency, risk assessment, hazardous quotient.

Acknowledgements: the authors are grateful to Chairman and Member Secretary of Central Pollution Control Board for guidance and providing the necessary facilities and infrastructure to conduct the present work. The views expressed in this paper are those of authors and do not necessarily reflect the organization's ones.

Contributions: BK, data processing and compilation, statistical analysis and manuscript preparation; VKK and SKS, sample collection, processing and analysis; SK, technical correction in manuscript preparation; CSS, planning; $\mathrm{ABA}$, guidance and permission to conduct study, and for publication.

Conflict of interests: the authors declare no potential conflict of interests.

Received for publication: 4 February 2014.

Revision received: 25 April 2014.

Accepted for publication: 30 April 2014.

CCopyright B. Kumar et al., 2014

Licensee PAGEPress, Italy

Journal of Public Health Research 2014; 3:252

doi:10.4081/jphr.2014.252

\section{References}

1. UNEP (United Nations Environmental Program). Stockholm Convention on Persistent Organic Pollutants. United Nations Environment Programme, Chemicals division, Geneva, Switzerland. 2001. Available from: http://www.pops.int.

2. ATSDR. Toxicological profile for polychlorinated biphenyls (update). Atlanta: US Department of Health and Human Services; 2000.

3. WHO. Polychlorinated biphenyls and terphenyls. Environmental Health Criteria 140. Geneva; WHO; 1993.

4. Herrick RF, McClean MD, Meeker JD, et al. An unrecognized source of PCB contamination in schools and other buildings. Environ Health Perspect 2004;112:1051-3.

5. Herrick RF, Lefkowitz DJ, Weymouth GA. Soil contamination from PCB-containing buildings. Environ Health Perspect 2007;115:173-75.

6. Giesy JP and Kannan K. Dioxin-like and non-dioxin-like toxic effects of polychlorinated biphenyls (PCBs): implications for risk assessment. Critical Rev Toxicol 1998;28:511-69.

7. Van den Berg M, Linda SB, Michael D, et al. The 2005 World Health Organization re-evaluation of human and mammalian toxic equivalency factors for dioxins and dioxin-like compounds. Toxicol Sci 2006;93:223-41.

8. Wang Q, Shi Y, Hu J, et al. Determination of dioxin-like polychlorinated biphenyls in soil and moss from Fildes Peninsula, Antarctica. Chinese Sci Bull 2012;57:992-6.

9. Wilcke W, Krauss M, Safronov G, et al. Polychlorinated biphenyls (PCBs) in soils of the Moscow region: concentrations and smallscale distribution along an urban-rural transect. Environ Pollut 2006;141:32-35.

10. Wu S, Xia X, Yang L, et al. Distribution, source and risk assessment 
of polychlorinated biphenyls (PCBs) in urban soils of Beijing, China. Chemosphere 2011;82:732-8.

11. Prasse C, Zech W, Itanna F, et al. Contamination and source assessment of metals, polychlorinated biphenyls, and polycyclic aromatic hydrocarbons in urban soils from Addis Ababa, Ethiopia. Toxicol Environ Chem 2012;94:1954-79.

12. Bentum JK, Dodoo DK, Kwakye PK. Accumulation of metals and polychlorinated biphenyls (PCBs) in soils around electric transformers in the central region of Ghana. Adv Appl Sci Res 2012;3:634-43.

13. Liao C, Lv J, Fu J, et al. Occurrence and profiles of polycyclic aromatic hydrocarbons (PAHs), polychlorinated biphenyls (PCBs) and organochlorine pesticides (OCPs) in soils from a typical e-waste recycling area in Southeast China. Int $\mathbf{J}$ Environ Health Res 2012;22:317-30.

14. Cachada A, Pereira ME, da Silva EF et al. Sources of potentially toxic elements and organic pollutants in an urban area subjected to an industrial impact. Environ Monit Assess 2012;184:15-32.

15. Shahbazi A, Bahramifar N, Smolders E. Elevated concentrations of pesticides and PCBs in soils at the Southern Caspian Sea (Iran) are related to land use. Soil Sedim Contam 2012;21:160-75.

16. Syed JH, Malik RN, Li J, et al. Levels, distribution and air-soil exchange fluxes of polychlorinated biphenyls (PCBs) in the environment of Punjab Province, Pakistan. Ecotoxicol Environ Saf 2013;97:189-95.

17. Wang P, Zhang $\mathrm{H}$, Fu J, et al. Temporal trends of PCBs, PCDD/Fs and PBDEs in soils from an E-waste dismantling area in East China. Environ Sci Processes Impacts 2013;15:1897-3.

18. UNEP. National Implementation Plan on POPs, India. Available from: http:/chmpopsint/Implementation/NIPs/NIPSubmissions/tabid/253/ Defaultaspx.

19. Chakraborty P, Zhang G, Eckhardt S, et al. Atmospheric polychlorinated biphenyls in Indian cities: levels, emission sources and toxicity equivalents. Environ Pollut 2013;182:283-90.

20. Kumar B, Singh SK, Mishra M, et al. Assessment of polychlorinated biphenyls and organochlorine pesticides in water samples from the Yamuna River. J Xenobiotics 2012;2:28-34.

21. Kumar B, Kumar S, Sharma CS. Ecotoxicological risk assessment of polychlorinated biphenyls (PCBs) in bank sediments from along the Yamuna River in Delhi, India. Human Ecol Risk Assess 2013; 19:1477-87.

22. Kumar B, Kumar S, Sharma CS. Congener specific distribution and health risk assessment of polychlorinated biphenyls in urban soils. J. Xenobiotics 2012;2:47-52.

23. Kumar B, Verma VK, Kumar S, Sharma CS. Probabilistic health risk assessment of polycyclic aromatic hydrocarbons and polychlorinated biphenyls in urban soils from a tropical city of India. J Environ Sci Health A Tox Hazard Subst Environ Eng 2013;48:1253-63.

24. United States Environmental Protection Agency (USEPA). Risk assessment guidance for superfund. Human health evaluation manual (Part A). Washington, DC: USEPSA; 1989.

25. Agency for Toxic Substances and Disease Registry. Public health assessment guidance manual. 2005 update. Available from: http://www.atsdr.cdc.gov/hac/PHAManual/toc.html.

26. United States Environmental Protection Agency. Users' guide (May 2004). Available from: http//www.epa.gov/reg3hwmd/risk/human/rbconcentration_table/usersguide.htm.

27. National Oceanic and Atmospheric Administration (NOAA). NOAA screening quick reference tables (SQuiRTs), HAZMAT REPORT 1999; 99-1, and Updated Feb 2004. Coastal Protection and Restoration Division, Seattle, Washington.

28. Canadian Council of Ministers of the Environment (CCME). Canadian soil quality guidelines for the protection of environmental and human health. 2207. Available from: http://www.esdat.net/
Environmental\%20Standards/Canada/SOIL/rev_soil_summary_tbl_ 7.0_e.pdf

29. Marwaha RK, Tandon N, Ganie MA, et al. Nationwide reference data for height, weight and body mass index of Indian school children. Natl Med J India 2011;24:269-77.

30. Indian Council of Medical Research (ICMR). Nutrient requirements and recommended dietary allowances for Indians. 2009. A report of the expert group of the Indian Council of Medical Research, National Institute of Nutrition, Hyderabad-500604, India.

31. Cavanagh JAE. Comparison of soil guideline values used in New Zealand and their derivations. Landcare Research Contract Report. 2006. Available from: http://ecan.govt.nz/publications/Reports/ ComparisonofSoilGuidelineValuesinNewZealand.pdf

32. Granier L, Chevreuil M. Automobile traffic: a source of PCBs to the atmosphere. Chemosphere 1991;23:785-8.

33. Wang Y, Luo CL, Li J, et al. Characterization and risk assessment of polychlorinated biphenyls in soils and vegetations near an electronic waste recycling site, South China. Chemosphere 2011; 85:344-50.

34. Xie W, Chen A, Li J, et al. Topsoil dichlorodiphenyltrichloroethane and polychlorinated biphenyl concentrations and sources along an urban-rural gradient in the Yellow River Delta. J Environ Sci 2012;24:1655-61.

35. Wilcke W, Amelung W. Persistent organic pollutants in native grassland soils along a Climosequence in North America. Soil Sci Soc Am J 2000;64:2140-8.

36. Gonzalez J, Feng L, Sutherland A, et al. PCBs and dioxins/furans in attic dust collected near former PCB production and secondary copper facilities in Sauget, IL. Procedia Environ Sci 2011;4:113-25.

37. Martinez A, Erdman NR, Rodenburg ZL, et al. Spatial distribution of chlordanes and PCB congeners in soil in Cedar Rapids, Iowa, USA. Environ Pollut 2012;161:222-8.

38. Ge J, Woodward LA, Li QX, et al. Distribution, sources and risk assessment of polychlorinated biphenyls in soils from the Midway Atoll, North Pacific Ocean. PLoS One 2013;8:e71521.

39. WHO. Evaluation of certain food additives and contaminants (57th report). Technical Report Series 909. 2001. Available from: http://whqlibdoc.who.int/trs/WHO_TRS_909.pdf

40. Ministry for the Environment, New Zealand. Toxicological intake values for priority contaminants in soil. 2011. Available from: http://www.mfe.govt.nz/publications/hazardous/toxicologicalintake-values-for-priority-contaminants-in-soil/toxicologicalintake-values-for-priority-contaminants-in-soil.pdf

41. Environment Agency, UK. Contaminants in soil: updated collation of toxicological data and intake values for humans. Dioxins, furans and dioxin-like PCBs. 2009. Science Report SC050021/SR TOX12. Available from: Contaminants in soil: updated collation of toxicological data and intake values for humans. Dioxins, furans and dioxin-like PCBs.

42. Government of Japan. Office of Dioxins Control, Environmental Management Bureau, Government of Japan. 2009. Available from: www.env.go.jp/en/chemi/dioxins/brochure2009.pdf.

43. Ferre-Huguet N, Bosch C, Lourencetti C, et al. Human health risk assessment of environmental exposure to organochlorine compounds in the Catalan stretch of the Ebro River, Spain. Bull Environ Contam Toxicol 2009;83:662-7.

44. Zhang JY, Li DF, Wang HF, et al. The health risk assessment and bioaccumulation of PCBs in soil-vegetables nearby E-waste area. Acta Pedol Sinica 2009;46:434-41.

45. Priha E, Hellman S, and Sorvari J. PCB contamination from polysulphide sealants in residential areas - exposure and risk assessment. Chemosphere 2005;59:537-43.

46. Shelepchikov AA, Brodskii ES, Feshin DB, et al. Polychlorinated dibenzo- p-dioxins, dibenzofurans, and biphenyls in soils of Moscow. Eurasian Soil Sci 2011;44:286-96. 